\title{
Effect of Gap Size And Elevation On The Regeneration And Coexistence of Three Tree Species In A Subalpine Coniferous Forest
}

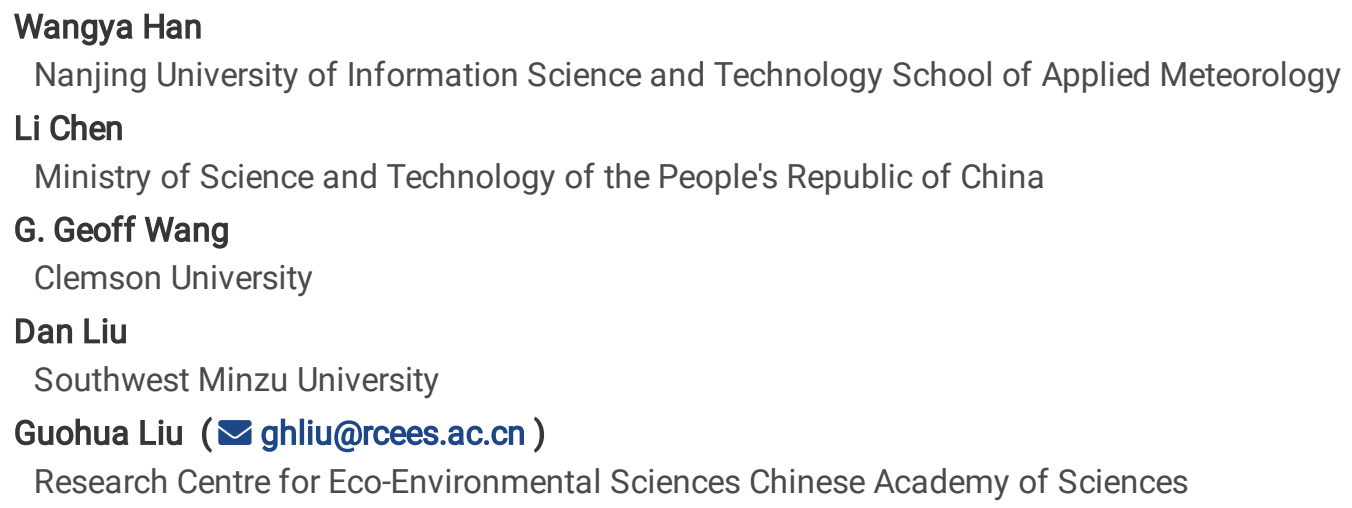

Research

Keywords: Gap size, Elevation, Tree species, Regeneration density, Coexistence, Subalpine coniferous forest

Posted Date: August 4th, 2021

DOI: https://doi.org/10.21203/rs.3.rs-734618/v1

License: (c) (i) This work is licensed under a Creative Commons Attribution 4.0 International License. Read Full License 


\section{Abstract}

Background: Gap size and environmental gradient have fundamental influence on the tree species coexistence and community assembly. We studied the regeneration and coexistence of three co-dominant tree species in three different gap size (large gap, 201$402 \mathrm{~m}^{2}$; medium gap, 101-200 $\mathrm{m}^{2}$; small gap, 38.8-100 $\mathrm{m}^{2}$ ) along an elevation gradient (between $3000 \mathrm{~m}$ and $3500 \mathrm{~m}$ ) in an oldgrowth forest, on Mount Nadu in southwest China.

Results: We found that the photosynthetic photon flux density (PPFD) was positively affected by gap size during the growing season. All three species had a higher regeneration density in large gaps, but the detailed response to treatments for each species depended on its stem size. Gap size had a significant positive effect on the regeneration density of Abies faxoniana small trees and Betula utilis saplings, but had no significant effect on Acer maximowiczii regeneration density. Saplings regeneration density is more sensitive to elevation compared to small trees regeneration density. Large gaps magnified the negative effects of elevation on regeneration density. Our findings indicated that Abies may maintain its regeneration advantage with low-intensity canopy disturbance, and large gap may provide excellent opportunities for broadleaf species (Betula and Acer) establishment and regeneration in this subalpine coniferous forest.

Conclusion: Microhabitats heterogeneity controlled by characteristics of forest gaps along an elevation affected regeneration niche difference of tree species, which contributed to species coexistence and community assembly processes.

\section{Background}

Gap creation not only increase the heterogeneity of environment but also promote the regeneration and coexistence of species in forest understory (Muscolo et al. 2014). Gap formation has long been an effective way to achieve continuous forest regeneration and succession (Wang et al. 2017). Compared with traditional silviculture policy, close-to-nature forest managements highlight the importance of gap disturbance (Zhu et al. 2014). As an important gap characteristic, gap size, which reflects the disturbance degree, can strongly influence microclimate species regeneration, and other ecological processes (Muscolo et al. 2014, Chen et al. 2018). Thus, understanding how gap size affect species regeneration and coexistence has been an important theme in forest ecology and management (Lang and Knight 1983, Dirzo et al. 1992, Barberis and Tanner 2005, Lu et al. 2018).

Most studies on canopy gaps have been focused on gap regeneration on a temporal scale (Lang and Knight 1983, Tamura and Nakajima 2017).Little attention, however, has been directed to gap regeneration on a spatial scale, especially along an elevation gradient (Chen et al. 2018). As an important geographical factor, elevation drives the environment factors and tree species regeneration, survival and coexistence (Cole et al. 2014, Sizonenko and Dubrovskiy 2018). For example, a study on Atlantic Rainforest gaps suggested that low altitude (at approximately $350 \mathrm{~m}$ a.s.I.) is more conducive to plant regeneration and coexistence (Eisenlohr et al. 2013). Another study in subalpine Abies fabri suggested in mountainous regions, air temperature is more sensitive to disturbance at high elevation areas than that at low elevation areas (Sun et al. 2017). In addition, the underground environment factors also exhibited significant difference along the elevation gradients from 2800 to $3600 \mathrm{~m}$ in a subalpine forest (Luo et al. 2015). These studies investigated the effects of elevation on plant generation and environment factors, but changes in regeneration and environment factors may be related to gap size along the elevation gradient. Given the complexity of the ecological mechanism underlying gap regeneration, a combined investigation may be required to better understand species regeneration and coexistence along the gradients of gap sizes and elevation.

Studies on plant regeneration and coexistence mechanism of different species have been widely studied (Tang and Ohsawa 2002, Masaki et al. 2007, Jin et al. 2018). The sapling-to-small tree stage is often a critical phase during the life history of plants in determining the distribution of adults (Masaki et al. 2007). The sapling stage is an important demographic, and it establishes the template for later regeneration process (Jin et al. 2018). Variation of regeneration density from sapling stage to small trees linked to the different regeneration niche and species response to microenvironmental resources (Tang and Ohsawa 2002, Jin et al. 2018). Moreover, regeneration density is an imperative knowledge to develop sustainable forest management (Padilha and De Marco 2018), and density dependence has been also hypothesized as one of the most prominent mechanism in species coexistence (Chen et al. 2010). Consequently, the species regeneration and coexistence mechanism of density dependence and habitat association becomes essential for better understanding gap species regeneration and its appropriate management strategy. 
The subalpine coniferous forest is the second largest forest area in China (Sun et al. 2017). It plays an important role in ecosystem services (e.g. water resources, timber supply and tourism services) in southwestern China (Bossard et al. 2015). Meanwhile, the subalpine coniferous forest in mountainous area is highly sensitive to climate change (Sun et al. 2017). Historically, at elevations greater than $3000 \mathrm{~m}$, the old growth forest canopy was dominated by Abies in Wolong National Nature Reserve (Taylor and Qin 1998, Chen et al. 2018). A recent study showed broadleaf species (e.g. Betula) have increased in the subalpine coniferous forest (Bossard et al. 2015). Therefore, it may be a challenge to the development of forest managements in the future.

Abies, Betula and Acer are major component tree species in most subalpine coniferous gaps from $3000 \mathrm{~m}$ to $3500 \mathrm{~m}$. Changes in sunlight, precipitation, temperature and soil properties often improve growth conditions for Betula and Acer establishment in gaps. To further understand potential changes in future subalpine forest composition (Bossard et al. 2015), we determined the three species regeneration density in different size gaps at the same elevation and examined the three species regeneration density in the same size gap along the elevation. We also studied how environment factors varied across different habitat gradients and their effects on the regeneration and coexistence of different tree species at different life history stages.

\section{Methods}

\subsection{Study site}

This study was carried out in a subalpine coniferous forest, an old-growth forest on Mount Nadu of the Wolong Nature Reserve $\left(30^{\circ} 45^{\prime}-31^{\circ} 25^{\prime} \mathrm{N}, 102^{\circ} 52^{\prime}-103^{\circ} 24^{\prime} \mathrm{E}\right)$, Sichuan Province, southwestern China. The study area has a subtropical inland and mountainous climate, with a strong solar radiation and cold temperature. The ultraviolet radiation ( $365 \mathrm{~nm}$, UV-A 365) ranges from $1621 \mu \mathrm{W} \mathrm{cm}-2$ to $549 \mu \mathrm{W} \mathrm{cm}{ }^{-2}$ in the growing season and the mean annual temperature is between $4.1^{\circ} \mathrm{C}$ and $5.1^{\circ} \mathrm{C}$. The mean annual rainfall is between $861 \mathrm{~mm}$ and $1800 \mathrm{~mm}$, with the highest precipitation month of August averaging $340 \mathrm{~mm}$. The soil is brown coniferous forest soil and the pH is between 3.9 to 5.0 (Chen et al. 2018). The majority of the snowfall occurs from October to February at high elevation. More detailed information on the study area could be found in our earlier publications (Chen et al. 2018, Liu et al. 2018, Chen et al. 2019).

Our field study was conducted in a coniferous forest with few human disturbance at the elevation span of 3000-3500 m. Historically, snowstorm and other natural disturbances were the main causes of forest gap formation. In this old-growth forest, the conifer tree of Abies faxoniana is found mostly from $2000 \mathrm{~m}$ to $3800 \mathrm{~m}$ and considered as a shade-tolerant species. At the elevation range from $3000 \mathrm{~m}$ to $3500 \mathrm{~m}$, the subalpine coniferous forest also include Betula utilis and Acer maximowiczii, two broadleaf, shade-intolerant tree species. The three dominant tree species make up $95 \%$ of trees at this range of elevation and they were natural regeneration. The shrub species mainly included Rhododendron faberisp, Rhododendron phaeochrysum and Fargesia nitida. The herb layer was dominated by Circaea alpine, Oxalis acetosrlla and Parasencio deltophyllus.

\subsection{Gap selection and experiment design}

A randomized design was used to sample gaps in each $100 \mathrm{~m}$ intervals during 2015-2018. At each elevation level, three gaps in each size class were selected. The three gap size class were: small gap $\left(n=3\right.$, area range: 38.5-100 $\left.m^{2}\right)$, medium gap $(n=3$, area range: 101-200 $\left.\mathrm{m}^{2}\right)$ and large gap $\left(n=3\right.$, area range: $201-402 \mathrm{~m}^{2}$ ), which were determined for as the expanded gaps (Wang et al. 2017). In total, we sampled 45 gaps with similar age, with an elevation range from $3000 \mathrm{~m}$ a.s.l. to $3500 \mathrm{~m}$ a.s.I.. We measured the longest canopy opening dimension as gap length and the perpendicular to gap length across the gap center as gap width, and then used these data to calculate the gap area using the formula of $A=\pi a b$ with $a$ and $b$ being half the gap length and width if gap was more similar to oval. If gap was more similar to circular, the formula of $A=\pi r^{2}$ was used, with $r=(a+b) / 2$.

\subsection{Data collection}

\subsubsection{Regeneration characteristics}

Within each gap, all saplings and small trees of the three tree species (repeat the names here) were censused during the growing season, and their species, height and ground line diameter (GLD) were recorded. Considering the difference in their growth among the three species, we divided these two different regeneration stage (sapling and small tree) based on our previous studies (Chen et al. 2018). The sapling stage was defined as " $0.1 \mathrm{~m}<$ stems $<1 \mathrm{~m}$ in height and $0.1 \mathrm{~cm}<\mathrm{GLD}<1.5 \mathrm{~cm}$ " (Kneeshaw and Bergeron 
1998). The regeneration stage of small tree was defined as "either stems $\geq 1 \mathrm{~m}$ in height or GLD $\geq 1.5 \mathrm{~cm}$ ". Stems with height $>5 \mathrm{~m}$ or diameter at breast height $(\mathrm{DBH})>10 \mathrm{~cm}$ were removed from regeneration datasets because they were considered as adult. There were fewer regeneration especially for Betula and Acer regeneration in small gaps and at high elevation gaps.

\subsubsection{Environment factors}

The aboveground and underground environment factors that could affect seedling establishment, growth and survival were measured in each gap along the elevation gradient, which include solar radiation, air temperature, air humidity, soil temperature and soil nutrient (Zhu et al. 2014). Generally, the photosynthetic photon flux density (PPFD) determine the species distribution and different life stage's growth of woody plants (Chen et al. 2018). Under overcast sky condition, PPFD was stable and have a good correlation with the growing season PPFD (Messier and Comeau 1998). Moreover, the PPFD in sunny days during the growing season may have the lowest restriction on the establishment of shade-intolerant species. In our study, PPFD (LI-190, Li-Cor Inc) was measured $1 \mathrm{~m}$ above ground level. Within each gap, the mean daily PPFD $\left(\mu \mathrm{mol} \mathrm{m}^{-2} \mathrm{~s}^{-1}\right)$ datasets were recorded continuously as 2hour averages from 8:00 am to 6:00 pm on cloudless days and overcast days during the growing season (June- September, 20152018) (Parent and Messier 1996). Temperature and precipitation conditions were significantly and positively affected by the creation of canopy gaps (Zhu et al. 2014, Buajan et al. 2018). Therefore, we measured the annual mean air temperature (AMAT, ${ }^{\circ} \mathrm{C}$ ), air relative humidity $(\mathrm{RH}, \%)$ and soil temperature $\left(\mathrm{ST},{ }^{\circ} \mathrm{C}\right)$ (Chen et al. 2018). We also measured and calculated annual average temperature difference between day and night $\left(\Delta \mathrm{T}_{\mathrm{AMT}},{ }^{\circ} \mathrm{C}\right)$, annual mean temperature of growing/non-growing season (GST/NGST, $\left.{ }^{\circ} \mathrm{C}\right)$, soil temperature in the upper layer $\left(0-10 \mathrm{~cm}, \mathrm{ST}_{1},{ }^{\circ} \mathrm{C}\right)$ and deep layer $\left(10-20 \mathrm{~cm}, \mathrm{ST}_{2},{ }^{\circ} \mathrm{C}\right)$.

These datasets were measured by button thermometer (iButton, DS1923-F5\#, USA) and recorded every 2-hour for one year at least. For the above-ground environment factors, two iButton recorders were fixed separately in the gap center and gap edge in each gap. The soil temperature datasets were monitored in the gap center at the depth of $0-10 \mathrm{~cm}$ and $10-20 \mathrm{~cm}$. Three random soil sample were collected beneath the litter layer in each gap and stored in a clean bags. All soil samples were air dried at room temperature. Stones, roots and debris were removed and then sieved through 2-mm mesh screen (Chen et al. 2019). Soil total carbon (STC, \%), Soil total nitrogen (STN, \%) and carbon to nitrogen ratio $(\mathrm{C} / \mathrm{N}, \%)$ were measured in each sampling quadrat using a Vario EL III analyser (Elementar Analy- sensysteme GmbH, Germany).

\subsection{Data analysis}

The regeneration data of all plots were averaged in each gap before analysis. We used one-way analysis of variance (ANOVA) to test the difference of regeneration density among three tree species in the same gap size and elevation gradient. The multivariate analysis of variance (MANOVA) analysis was then used to determine the effect of gap size or elevation on three species regeneration density of sapling and small tree. Two-way ANOVAs was used to test the effects of gap size and elevation on the environment factors. Each $p$-value less than 0.05 was regarded as the evidence of statistically significant. Tukey's post hoc tests were used to further exam the difference among treatment levels. Bonferroni-adjusted test was applied for multiple testing, a $p$-value less than 0.01 indicated significant difference. To assess the relationship of regeneration density with environment factors, we used the Pearson correlation analyses based on all treatment data. Data were performed using R version 3.3.3 (R Core Team, 2017). Multcomp package was used for descriptive statistics, one-way ANOVA, two-way ANOVA and Tukey's post hoc tests. MASS package was used for MANOVA analysis. Psych package was used for correlation analyses.

\section{Results}

\subsection{Variation in regeneration density of three species and environment factors among gaps}

Saplings had a higher density than small trees within each habitat type (Table 1). As expected, regeneration density increased with increasing gap size but declined with increasing elevation (Fig. 1). In small gaps, Abies saplings density was significantly greater than Betula and Acer saplings density, but the three tree species were similar for the small tree density regardless of gap size. Moreover, these regeneration density and gap size relationships did not change with elevation (Fig. 1A).

In medium and large gaps, Betula sapling and small tree density were significantly higher than Abies and Acer (Fig. 1B and C), while Abies regeneration density will predominate at the higher elevation gradients(Fig. 1B and C). These results indicated that small gaps 
were conducive to Abies sapling. Moreover, the dominance of species regeneration density changed in large and medium gaps with increasing elevation, but the sapling regeneration density in small gaps did not.

The PPFD was mainly affected by gap size on overcast days during the growing season $(F=27.57, p<0.001)$. Besides GST was not significantly affected by gap size $(F=2.09, p=0.141)$, the AMAT, $\triangle T_{\text {AMT }}$ and NGST were significantly affected by elevation and gap size $(p<0.001)$. Soil temperature showed no difference among different sizes gaps $\left(\mathrm{ST}_{1}: \mathrm{F}=0.09, p=0.914 ; \mathrm{ST}_{2}: \mathrm{F}=1.86, p=0.173\right)$, while significantly affected by elevation ( $\left.\mathrm{ST}_{1}: \mathrm{F}=127.26, p<0.001 ; \mathrm{ST}_{2}: \mathrm{F}=106.56, p<0.001\right)$. Our result showed a significant interaction effect between elevation and gap size on soil $\mathrm{C} / \mathrm{N}$ ratio $(0-10 \mathrm{~cm}: \mathrm{F}=2.36, p=0.042 ; 10-20 \mathrm{~cm}: \mathrm{F}=6.47, p<0.001)$, though it is similar in all treatments (elevation: $\mathrm{F}=2.48, p=0.065$; gap size: $\mathrm{F}=1.68, p=0.204$ ). Otherwise, in our study, the other below-ground environment factors were significantly affected by elevation and gap size $(p<0.001)$. In conclusion, the improvement of understory illumination mainly comes from canopy gaps opening, and elevation has a relatively wider influence on environmental factors than forest gap (Table 2).

\subsection{Effect of gap size and elevation on regeneration density of three species}

Abies sapling regeneration density was significantly higher in small gaps than in medium gaps and large gaps along the elevation gradients (Fig. 2A and Table 3). In the same elevation gradient, these three tree species small trees regeneration density were positively affected by the gap size, while Betula small tree regeneration density was not significantly affected by gap size at the elevation gradient of $3400 \mathrm{~m}-3500 \mathrm{~m}$ and Acer small tree regeneration density was not significantly affected by gap size from $3200 \mathrm{~m}$ a.s.I to $3500 \mathrm{~m}$ a.s.I (Fig. 2B). These results meant that the gap size most affected Betula sapling regeneration density, followed by Abies and Acer saplings density. However, for the small trees, the gap size affected the Abies small trees regeneration density more obvious than Betula and Acer regeneration density (Table 3 ) .

In small gaps (Fig. $3 \mathrm{~A}_{1}$ and $\mathrm{B}_{1}$ ), three species saplings regeneration density were significantly and negatively affected by the elevation (Abies: $\mathrm{F}=40.06, p<0.001$; Betula: $\mathrm{F}=29.25, p<0.001$; Acer. $\mathrm{F}=4.48, p=0.025$ ), while their small trees regeneration density was similar among different elevation gradients. In medium gaps (Fig. $3 \mathrm{~A}_{2}$ and $\mathrm{B}_{2}$ ), the Betula small trees regeneration density was not significantly affect by the elevation $(F=5.10, p=0.017)$, other regeneration density was significantly affected by elevation. In large gaps (Fig. $3 \mathrm{~A}_{3}$ and $\mathrm{B}_{3}$ ), both three species saplings regeneration density, and their small trees regeneration density was significantly affected by elevation (Table 4). These results indicated that elevationshowed a greater impact on saplings regeneration density than small trees regeneration density, and the effect of elevation on their regeneration density was more obvious in large gap size than in small gap.

\subsection{Relationship between regeneration density and environment factors}

Correlation analysis revealed thatthe relationships between Abies regeneration density and environment factors differed between the two life history stages (Table 5). For Abies saplings, there were significant and positive correlation between regeneration density and air temperature, ST and STN $(0-10 \mathrm{~cm})$. For Abies small trees, the $\Delta \mathrm{T}_{\mathrm{AMT}}, \mathrm{PPFD}, \mathrm{RH}$ and more soil properties had a significant and positive correlation with regeneration density (Table 5). The other two species (Acer and Betula) showed similar relationships between regeneration density and environment factors for the two life history stages (Table 5), suggesting Acer and Betula likely have similar life habits. For each species (Acer and Betula), the results also revealed that the regeneration density at two life stages have the similar relationships with environment factors (Table 5). More below-ground environment factors showed significant positive correlations with Acer and Betula sapling regeneration density than with Abies sapling regeneration density.

\section{Discussion}

\subsection{Effect of gap size on environment filtering for species regeneration}

In forest gaps, gap size can affect the microenvironment in gaps, and the two factors combined together then affecting vegetation regeneration (Denslow et al. 1998, He et al. 2019). Our results confirmed that the PPFD is mainly affected by gap size on overcast day during growing season, and it has positive and significant correlation with Acer and Betula saplings regeneration density and the three species small trees regeneration density in subalpine gaps. However, Abies sapling regeneration density shows insignificant correlation with PPFD during growing season. Since Abies is a common shade tolerance species, and the small gaps with lower

Page 5/17 
PPFD provided a more superior habitat for Abies saplings (Miao et al. 2014). In order to meet the growth, light demanding also increased in the Abies small tree life stage (Chen et al. 2018, Jin et al. 2018). However, in small gaps, there are still several Abies small trees survived in these relatively low-light environment. Some studies suggested (Wang et al. 2017, Lu et al. 2018) that the center of small gaps with higher light was one of the most reasons allowing shade-tolerance species to be established. We speculate that the previous regeneration might be attribute to Abies small trees survival in small gaps, because serval Abies saplings may have established in understory and they will grow rapidly once the gaps formed.

With respect to Acer and Betula regeneration in different size gaps compared with Abies, the correlation analysis results suggested the regeneration density exhibited greater similar between regeneration density and aboveground environment factors (e.g. AMAT and RH) which were affected by gap size. As mentioned by Gray and Spies (1998) (Gray and Spies 1998), establishment and regeneration of different species was related to the tolerance of environmental and utilization of resources in gaps. Moreover, in the medium gaps and large gaps, the Betula regeneration density was significant higher than Acer regeneration density. Thus, we speculate that the Betula has stronger competitiveness and more effective regeneration strategy in sapling life stage than Acer in the suitable microsite in our study area.

A study on Calabrian pine (Pinus laricio) showed no significant differences in GST between gaps of different sizes (Muscolo et al. 2007). Similarly, several studies in conifer forest reported GST was not significant affect by gap size (Muscolo et al. 2014, Gray et al. 2002). Our study also did not detect a significant difference in GST among different size gaps. But, Abies, Acer and Betula regeneration were significantly correlated with GST. Further study showed that the interact effects of elevation and gap size significantly influenced the GST. Our results suggested that the concurrent effects of elevation and gap size on some environment factors, such as GST, may be also important drivers on the establishment, regeneration and survival of vegetations, and their interaction effects should not be neglected in future researches.

Many studies of gap regeneration have focused on the relationships among gap size, soil properties and regeneration success. According to Scharenbroch and Bockheim (2008) the surface $\mathrm{C}$ efflux was significantly higher in gaps, likely in response to solar radiation and soil temperature which, in turn, generally positively related tree regeneration successful. In a former research, C/N ratio was negatively and significantly related with gap size (Muscolo A and R. 2011). In our study, soil temperature in two soil layers were not significantly affected by the gap size. While STC, STN and C/N ratio were significantly and positively affected by gap size or influenced by the interact effects of elevation and gap size. For the saplings regeneration, Betula and Acer was more significantly related to fertile soil nutrients in large gap than Abies (Muscolo et al. 2014). These findings therefore suggested the view that during early-successional, natural regeneration of pioneer tree species as Betula restricted by soil nutrition besides solar radiation and demands large gaps in the subalpine coniferous forest.

\subsection{Effect of elevation on environment filtering for species regeneration}

Elevation is a strong driver of spatial variation in environment factors (e.g. temperature, precipitation and soil properties), and it may therefore have large consequences for species distribution and plant regeneration (Korner 1992, Chen et al. 2018). Sanchez et al. (2013) suggested that soil characteristics of the altitudinal gradient determines the distribution of plants pattern. In a rainforest, Eisenlohr et al. (2013) found that disturbances, topography and spatial proximity drive vegetation patterns along an elevation gradient. Moreover, some previous studies (Scarano 2002, Rezende et al. 2015) have shown that low temperature is the particularly important stressful factor for plant species subject near mountaintops. In our study, almost all of the underground and belowground environment factors were significantly affect by elevation, except for PPFD. Moreover, except for soil temperature, few belowground environment factors showed significantly correlation with Abies saplings regeneration density. For Betula regeneration, PPFD, air temperature, $\mathrm{RH}$ and soil properties were significantly correlated with saplings density. These facts, which restrictive environmental factors invalidated from belowground, may partly explain why Abies saplings occupied regeneration advantage in gaps with the elevation increasing, while Betula saplings regeneration is more dominant at lower elevation gradients.

Forest gaps are commonly formed by canopy tree fall, which partly resembles to the early successional forest habitats in old-growth forest (Jin et al. 2015). We found that in large gaps, the effect of elevation on our observed species regeneration density was more obvious. For the canopy opening area, Denslow (1987) (Denslow 1987), point out that, the environment factors in gaps would be more sensitive from harsh weather conditions without the canopy protection. Considering the extensive influence of elevation on environmental factors, the filtration capacity from elevation for plant establish and regeneration may be enlarged with gap size increased. 


\subsection{Community assembly processes along gap and elevation gradient}

Species coexistence in communities is due to different ecological strategies for species occupying different niches. Environmental heterogeneity affecting niche space is a primary factor on species coexistence (Adler et al., 2013, Stein et al., 2014). Bergholz et al. (2017) showed that environmental heterogeneity resulted from environmental filtering within microhabitats had a main influence on community assembly (Bergholz et al., 2017). The microhabitats heterogeneity controlled by characteristics of forest gaps affected trees regeneration. Our study demonstrated that Betula saplings regeneration dominated as a shade intolerant species in large and medium gaps, and the regeneration advantage could be extended to the small trees stage in large gaps at lower elevation gradients (3000m-3300m).

The three pioneer species of subalpine coniferous forest in the study area have different regeneration ecology. The conifer $A b i e s$ is long-living climax species and could endure the competitive disadvantage with lower regeneration density in relatively resource-rich gaps in early stages of succession (Tang and Ohsawa 2002). As mentioned by Jin et al. (2018), light radiation limit shade tolerance species regeneration in large gaps. In addition, the slow allocation to height growth of Abies results in tall and hard stems, which appears to be a long-term competitive strategy to tolerant shading (Taylor and Qin 1998). However, Betula as a shade intolerant species grow fast under full sunlight, resulting in tall young trees with slender trunks and narrow crowns (Miao et al., 2014). Betula grow rapidly under full sunlight, and becomes a pioneer species in the early stages of succession. This competitive strategy results a higher rates of mortality from sapling to small trees stage (Mori and Takeda 2004). With the increase of the continuous canopy cover in later stages of succession, Betula is replaced by shade-tolerant species such Abies. Thus, Abies is more representative of kselected species compared to r-selected species like Betula (Miao et al. 2014). For deciduous Acer regeneration, it survives as a fugitive with lowest saplings and small trees regeneration density. This species seems to avoid competition with Abies and Betula, and adapt a relatively narrow niche even though insuitable habitat (e.g. large gaps and medium gaps) (Tang and Ohsawa 2002). Light radiation limit shade tolerance species regeneration in large gaps, as mentioned by Jin et al. (2018). If Betula and Acertrees want to be canopy trees, the large gaps may provide excellent opportunities and places (Brokaw 1987, Hoffman, Bataineh et al. 2018). Environmental conditions including soil conditions and light intensity controlled by topographic features affect the saplings regeneration of these three tree species and the processes of community assembly.

\section{Conclusion And Management Implication}

In conclusion, we tested the effect of forest gap size on three tree species regeneration density along an elevation gradient, and each species have shown different regeneration and coexistence ecology strategy. This study reveals that the large gap could enlarged the effects of elevation on species regeneration density. In addition, mountain regions are particularly sensitive to climate change, and current climate change favors broadleaf species rather than conifer species (Bossard et al. 2015, Fourcade et al. 2019). Moreover, a related study reveals elevation shifts can locally reshape species competitive (Alexander et al. 2015). Thus, low-intensity canopy treatments could be applied in future forest management plants if we want maintain Abies dominance regeneration along the elevation gradients.

Unlike the old-growth forests with few human disturbance in core zone in natural reserve, a large area of coniferous forests in Wolong National Nature Reserve play an important role in tourist and timber supply. The broadleaf tree species, especially Betula and Acer, play a vital role in forming the "color forest" in fall (Bossard et al. 2015). In addition, long-term monoculture Abies plantation may lead more vulnerable to disease, pest insect disturbance, or facing reduced soil fertility and other potential ecological problems (Lu et al. 2018). We suggest creating large or medium gaps examined in our study in these forests that aims to promote broadleaf species regeneration improving ecological function and sustainability.

Although, our study exploratory analysis only implemented along a section of elevation gradient at a regional scale in Wolong National Nature Reserve. We found clear evidence of species regeneration and coexistence potential ecological mechanism with typical habitat gradients in a subalpine coniferous forest. Our study indicates that (1) gap size had largely and significantly affected on the Abies small trees regeneration density and Betula saplings regeneration density but limited influence on Acer regeneration density. (2) For these three tree species, saplings regeneration density were more sensitively influenced by elevation than small trees regeneration density, and gap size can positively enlarged the effects of elevation on the three species regeneration density. (3) Based on the underlying ecological mechanism of species regeneration and coexistence of density dependence and habitat association, we also put forward different forest management measures according to forest ecosystem service functions in our 
study area. However, since multiple environment factors were associated with gap size and elevation, many direct and indirect effects among gap size and/or elevation, environment factors and species regeneration remain unknown. In the future, continuous monitoring and additional treatments would be required to disentangle their inner links between gap size, environment variables and species regeneration along elevation gradients.

\section{Declarations}

\section{Ethics approval and consent to participate}

Not applicable.

\section{Consent for publication}

Not applicable.

\section{Availability of data and materials}

The dataset used and/or analyzed during the current study are available from the corresponding author on reasonable request.

\section{Competing interests}

The authors declare that they have no competing interests.

\section{Funding}

This study was founded by the National Key Research and Development Program of China (2016YFC0502102).

\section{Authors' contributions}

W.-Y.H., L.C. designed the study, analyzed the data and wrote the manuscript. D.L. organized and analyzed the data. G.-G.W., G.-H.L. modified article structure. All the authors contributed discussion to improve the manuscript.

\section{Acknowledgements}

This work was supported by the National Key Research and Development Program of China (2016YFC0502102). The authors gratefully acknowledge financial support from China Scholarship Council.

\section{Authors' information}

Corresponding author

Correspondence to Guohua Liu.

Affiliations

State Key Laboratory of Urban and Regional Ecology, Research Center for Eco-Environmental Sciences, Chinese Academy of Sciences, Beijing 100085, China

\section{References}

1. Adler PB, Fajardo A, Kleinhesselink AR, Kraft NJ (2013) Trait-based tests of coexistence mechanisms. Ecology letters 16(10):1294-1306

2. Alexander JM, Diez JM, Levine JM (2015) Novel competitors shape species' responses to climate change. Nature 525(7570):515-518

3. Barberis IM, Tanner EV (2005). Gaps and root trenching increase tree seedling growth in Panamanian semi-evergreen forest. Ecology, 86(3), 667-674. Bergholz K, May F, Giladi I, Ristow M, Ziv Y, Jeltsch F (2017). Environmental heterogeneity drives fine- 
scale species assembly and functional diversity of annual plants in a semi-arid environment. Perspectives in Plant Ecology, Evolution and Systematics, 24, 138-146

4. Bossard CC, Cao Y, Wang J, Rose A, Tang Y (2015) New patterns of establishment and growth of Picea, Abies and Betula tree species in subalpine forest gaps of Jiuzhaigou National Nature Reserve, Sichuan, southwestern China in a changing environment. For Ecol Manage 356:84-92

5. Brokaw NVL (1987) Gap-phase regeneration of three pioneer tree species in a tropical forest. The Journal of Ecology, 9-19

6. Buajan S, Liu JF, He ZS, Feng XP, Muhammad A (2018) Effects of Gap Size and Locations on the Regeneration of Castanopsis Kawakamii in a Subtropical Natural Forest, China. Journal of Tropical Forest Science 30(1):39-48

7. Chen L, Han W, Liu D, Liu G (2019) How forest gaps shaped plant diversity along an elevational gradient in Wolong National Nature Reserve. J Geog Sci 29(7):1081-1097

8. Chen L, Liu GH, Liu D (2018) How Forest Gap and Elevation Shaped Abies faxoniana Rehd. et Wils. Regeneration in a Subalpine Coniferous Forest, Southwestern China. Forests 9(5)

9. Chen L, Mi XC, Comita LS, Zhang LW, Ren HB, Ma KP (2010) Community-level consequences of density dependence and habitat association in a subtropical broad-leaved forest. Ecol Lett 13(6):695-704

10. Cole EM, Bustamante MR, Almeida-Reinoso D, Funk WC (2014) Spatial and temporal variation in population dynamics of Andean frogs: Effects of forest disturbance and evidence for declines. Global Ecology Conservation 1:60-70

11. Denslow JS (1987) Tropical rainforest gaps and tree species diversity. Annu Rev Ecol Syst 18:431-451

12. Denslow JS, Ellison AM, Sanford RE (1998) Treefall gap size effects on above- and below-ground processes in a tropical wet forest. J Ecol 86(4):597-609

13. Dirzo R, Horvitz CC, Quevedo H, Lopez MA (1992) The effects of gap size and age on the understorey herb community of a tropical Mexican rain forest. J Ecol 80(4):809-822

14. Eisenlohr PV, Alves LF, Bernacci LC, Padgurschi MCG, Torres RB, Prata EMB, dos Santos F, Assis MA, Ramos E, Rochelle ALC, Martins FR, Campos MCR, Pedroni F, Sanchez M, Pereira LS, Vieira SA, Gomes JAMA, Tamashiro JY, Scaranello MAS, Caron CJ, Joly CA (2013) Disturbances, elevation, topography and spatial proximity drive vegetation patterns along an altitudinal gradient of a top biodiversity hotspot. Biodivers Conserv 22(12):2767-2783

15. Fourcade Y, Astrom S, Ockinger E (2019) Climate and land-cover change alter bumblebee species richness and community composition in subalpine areas. Biodivers Conserv 28(3):639-653

16. Gray AN, Spies TA (1998) Microsite controls on tree seedling establishment in conifer forest canopy gaps (vol 78, pg 2458, 1997). Ecology 79(7): 2571-2571

17. Gray AN, Spies TA, Easter MJ (2002) Microclimate and soil moisture re- sponses to gap formation in coastal Douglas-fir forests. Can J For Res 32:332-343

18. He Z, Wang L, Jiang L, Wang Z, Liu J, Xu D, Hong W (2019) Effect of Microenvironment on Species Distribution Patterns in the Regeneration Layer of Forest Gaps and Non-Gaps in a Subtropical Natural Forest, China. Forests 10(2)

19. Hoffman A, Bataineh M, Adams J, Nelson A (2018) Partial harvesting effects on seedling growth and physiology of three hardwood species in mature pine (Pinus spp., Pinaceae)-hardwood mixtures. Journal of the Torrey Botanical Society 145(3):237-249

20. Jin Y, Russo SE, Yu MJ (2018) Effects of light and topography on regeneration and coexistence of evergreen and deciduous tree species in a Chinese subtropical forest. J Ecol 106(4):1634-1645

21. Kneeshaw DD, Bergeron Y (1998) Canopy gap characteristics and tree replacement in the southeastern boreal forest. Ecology 79(3):783-794

22. Korner C (1992) Why are there global gradients in species richness? Mountains might hold the answer. Trends Ecol Evol 45:618-619

23. Lang GE, Knight DH (1983) Tree growth, mortality, recruitment, and canopy gap formation during a 10-year period in a tropical moist forest. Ecology 64(5):1075-1080

24. Liu D, Liu GH, Chen L, Wang JT, Zhang LM (2018) Soil pH determines fungal diversity along an elevation gradient in Southwestern China. Science China-Life Sciences 61(6):718-726 
25. Lu DL, Wang GG, Yu LZ, Zhang T, Zhu JJ (2018) Seedling survival within forest gaps: the effects of gap size, within-gap position and forest type on species of contrasting shade-tolerance in Northeast China. Forestry 91:470-479

26. Lu DL, Wang GG, Zhang JX, Fang YT, Zhu CY, Zhu JJ (2018) Converting larch plantations to mixed stands: Effects of canopy treatment on the survival and growth of planted seedlings with contrasting shade tolerance. For Ecol Manage 409:19-28

27. Luo SZ, Liu GH, Li ZS, Hu CJ, Gong L, Wang M, Hu HF (2015) Soil respiration along an altitudinal gradient in a subalpine secondary forest in China. Iforest-Biogeosciences Forestry 8:526-532

28. Masaki T, Osumi K, Takahashi K, Hoshizaki K, Matsune K, Suzuki W (2007) Effects of microenvironmental heterogeneity on the seed-to-seedling process and tree coexistence in a riparian forest. Ecol Res 22(5):724-734

29. Messier FGC, Comeau PG (1998) Comparison of various methods for estimating the mean growing season percent photosynthetic photon flux density in forest. Agric For Meteorol 92(1):55-70

30. Miao N, Liu SR, Yu H, Shi ZM, Moermond T, Liu Y (2014) Spatial analysis of remnant tree effects in a secondary Abies-Betula forest on the eastern edge of the Qinghai-Tibetan Plateau, China. For Ecol Manage 313:104-111

31. Mori A, Takeda H (2004) Effects of undisturbed canopy structure on population structure and species coexistence in an oldgrowth subalpine forest in central Japan. For Ecol Manage 200(1-3):89-100

32. Muscolo A, Bagnato S, Sidari M, Mercurio R (2014) A review of the roles of forest canopy gaps. Journal of Forestry Research 25(4):725-736

33. Muscolo A, Sidari MC M, and M. R (2011) Effects of gap size and soil chemical properties on the natural regeneration in black pine (Pinus nigra, Arn.) stands. Tree Forest Science Biotechnology 5:65-71

34. Muscolo A, Sidari M, Mercurio R (2007) Influence of gap size on organic matter decomposition, microbial biomass and nutrient cycle in Calabrian pine (Pinus laricio, Poiret) stands. For Ecol Manage 242(2-3):412-418

35. Padilha DL, De Marco P (2018) A gap in the woods: Wood density knowledge as impediment to develop sustainable use in Atlantic Forest. For Ecol Manage 424:448-457

36. Parent S, Messier C (1996) A simple and efficient method to estimate microsite light availability under a forest canopy. Can $J$ For Res 26(1):151-154

37. Rezende VL, Eisenlohr PV, Vibrans AC, de Oliveira AT (2015) Humidity, low temperature extremes, and space influence floristic variation across an insightful gradient in the Subtropical Atlantic Forest. Plant Ecol 216(6):759-774

38. Scarano FR (2002) Structure, function and floristic relationships of plant communities in stressful habitats marginal to the Brazilian Atlantic rainforest. Ann Bot 90(4):517-524

39. Stein A, Gerstner K, Kreft H (2014) Environmental heterogeneity as a universal driver of species richness across taxa, biomes and spatial scales. Ecology letters 17(7):866-880

40. Sizonenko TA, Dubrovskiy YA (2018) Ectomycorrhiza of Larix sibirica Ledeb. along the gradients of main ecological factors and elevation at the Northern and Subpolar Urals. J Mt Sci 15(12):2603-2613

41. Sun XY, Wang GX, Huang M, Hu ZY, Song CL (2017) Effect of climate change on seasonal water use efficiency in subalpine Abies fabri. J Mt Sci 14(1):142-157

42. Tamura A, Nakajima K (2017) Effects of 10 years of fencing under a gap and closed canopy on the regeneration of tree seedlings in an old-growth Japanese fir (Abies firma) forest overbrowsed by sika deer. Journal of Forest Research 22(4):224232

43. Tang CQ, Ohsawa M (2002) Coexistence mechanisms of evergreen, deciduous and coniferous trees in a mid-montane mixed forest on Mt. Emei, Sichuan, China. Plant Ecol 161(2):215-230

44. Taylor AH, Qin ZS (1998) Regeneration Patterns in Old-Growth Abies-Betula Forests in the Wolong Natural Reserve, Sichuan, China. J Ecol 76:1204-1218

45. Wang ZB, Yang HJ, Dong BQ, Zhou MM, Ma LY, Jia ZK, Duan J (2017) Effects of canopy gap size on growth and spatial patterns of Chinese pine (Pinus tabulaeformis) regeneration. For Ecol Manage 385:46-56

46. Zhu JJ, Lu DL, Zhang WD (2014) Effects of gaps on regeneration of woody plants: a meta-analysis. Journal of Forestry Research 25(3):501-510

\section{Tables}


Table 1 Descriptive statistic for three species regeneration density and environment factors in our gap study of a subalpine coniferous forest (mean \pm SE ). PPFD: photosynthetic photon flux density; GST: annual mean temperature of growing season; NGST: annual mean temperature of non-growing season; $\Delta \mathrm{T}_{\mathrm{AMT}}$ : annual average temperature difference between day and night.

\begin{tabular}{llll} 
Variables & & & \\
\hline Regeneration density & sapling & small tree & total \\
\hline Abies faxoniana $\left(\mathrm{N} \mathrm{m}^{-2}\right)$ & $0.91 \pm 0.19$ & $0.37 \pm 0.26$ & $0.64 \pm 0.35$ \\
\hline Betula utilis $\left(\mathrm{N} \mathrm{m}^{-2}\right)$ & $0.94 \pm 0.86$ & $0.42 \pm 0.49$ & $0.68 \pm 0.86$ \\
\hline Acer maximowiczii $\left(\mathrm{N} \mathrm{m}^{-2}\right)$ & $0.27 \pm 0.20$ & $0.19 \pm 0.12$ & $0.23 \pm 0.17$ \\
\hline Light radiation & Cloudless & Overcast & total \\
\hline PPFD ( $\mu$ mol $\left.\mathrm{m}^{-2} \mathrm{~s}^{-1}\right)$ & $464.56 \pm 88.48$ & $261.4 \pm 15.7$ & $362.95 \pm 120.13$ \\
\hline air temperature & $\mathrm{GST}$ & $\mathrm{NGST}$ & Annual \\
\hline Mean temperature $\left({ }^{\circ} \mathrm{C}\right)$ & $15.73 \pm 1.80$ & $-7.96 \pm 1.36$ & $3.71 \pm 0.43$ \\
\hline$\Delta \mathrm{T}_{\text {AMT }}\left({ }^{\circ} \mathrm{C}\right)$ & - & - & $4.19 \pm 0.60$ \\
\hline air relative humidity & & & \\
\hline Mean humidity $(\%)$ & - & - & $93.12 \pm 1.15$ \\
\hline Soil properties & $0-10 \mathrm{~cm}$ & $10-20 \mathrm{~cm}$ & total \\
\hline Soil tempreture $\left({ }^{\circ} \mathrm{C}\right)$ & $2.48 \pm 0.70$ & $2.63 \pm 0.76$ & $2.56 \pm 0.73$ \\
\hline Soil total C $(\%)$ & $9.15 \pm 5.18$ & $6.88 \pm 1.51$ & $8.02 \pm 3.96$ \\
\hline Soil total $\mathrm{N}(\%)$ & $0.45 \pm 0.14$ & $0.38 \pm 0.06$ & $0.41 \pm 0.11$ \\
\hline Soil C/N ratio & $20.14 \pm 6.99$ & $0.27 \pm 1.83$ & $19.05 \pm 5.20$ \\
\hline
\end{tabular}

Table 2 Two-way ANOVAs for the effects of elevation and gap size on environment factors. Significant effects $(p<0.05)$ are bolded. 


\begin{tabular}{|c|c|c|c|c|c|c|}
\hline & \multicolumn{2}{|c|}{ Elevation } & \multicolumn{2}{|c|}{ Gap size } & \multicolumn{2}{|c|}{ Elevation*size } \\
\hline & $\mathrm{F}$ & $p$ & $\mathrm{~F}$ & $p$ & $\mathrm{~F}$ & $p$ \\
\hline \multicolumn{7}{|l|}{$\operatorname{PPFD}\left(\mu \mathrm{mol} \mathrm{m}^{-2} \mathrm{~s}^{-1}\right)$} \\
\hline Cloudless & 0.50 & 0.485 & 1.49 & 0.229 & 0.75 & 0.393 \\
\hline Overcast & 0.68 & 0.615 & 27.57 & $<0.001$ & 0.27 & 0.971 \\
\hline \multicolumn{7}{|l|}{ Air Temperature $\left({ }^{\circ} \mathrm{C}\right)$} \\
\hline Annual mean temperature & 134.52 & $<0.001$ & 13.59 & $<0.001$ & 5.07 & $<0.001$ \\
\hline$\Delta \mathrm{T}_{\mathrm{AMT}}$ & 139.05 & $<0.001$ & 510.80 & $<0.001$ & 50.97 & $<0.001$ \\
\hline temperature in growing season & 151.53 & $<0.001$ & 2.09 & 0.141 & 5.87 & $<0.001$ \\
\hline temperature in non-growing season & 44.82 & $<0.001$ & 85.31 & $<0.001$ & 39.98 & $<0.001$ \\
\hline \multicolumn{7}{|l|}{ Air Humidity (\%) } \\
\hline Annual mean humidity & 7.39 & $<0.001$ & 51.40 & $<0.001$ & 15.15 & $<0.001$ \\
\hline \multicolumn{7}{|l|}{ Soil properity } \\
\hline Soil temperature $\left({ }^{\circ} \mathrm{C}\right) \quad 0-10 \mathrm{~cm}$ & 127.26 & $<0.001$ & 0.09 & 0.914 & 0.51 & 0.836 \\
\hline $10-20 \mathrm{~cm}$ & 106.56 & $<0.001$ & 1.86 & 0.173 & 0.82 & 0.588 \\
\hline Soil total C (\%) $\quad 0-10 \mathrm{~cm}$ & 11.68 & $<0.001$ & 8.54 & 0.0016 & 2.33 & 0.044 \\
\hline $10-20 \mathrm{~cm}$ & 371.40 & $<0.001$ & 298.50 & $<0.001$ & 21.80 & $<0.001$ \\
\hline Soil total N (\%) & 31.93 & $<0.001$ & 12.23 & $<0.001$ & 1.17 & 0.3469 \\
\hline $10-20 \mathrm{~cm}$ & 155.63 & $<0.001$ & 134.36 & $<0.001$ & 22.49 & $<0.001$ \\
\hline Soil C/N ratio (\%) $\quad 0-10 \mathrm{~cm}$ & 2.48 & 0.0653 & 1.68 & 0.2038 & 2.36 & 0.042 \\
\hline $10-20 \mathrm{~cm}$ & 26.16 & $<0.001$ & 29.73 & $<0.001$ & 6.47 & $<0.001$ \\
\hline
\end{tabular}

Table 3 MANOVA analysis of the effects of gap size on three species regeneration density at each elevation intervals. Significant effects $(p<0.01)$ are bolded.

\begin{tabular}{|c|c|c|c|c|c|c|c|c|c|c|c|c|}
\hline \multirow[t]{3}{*}{ Elevation } & \multicolumn{4}{|c|}{ Abies faxoniana } & \multicolumn{4}{|c|}{ Betula utilis } & \multicolumn{4}{|c|}{ Acer maximowiczii } \\
\hline & \multicolumn{2}{|c|}{ sapling } & \multicolumn{2}{|c|}{ small tree } & \multicolumn{2}{|l|}{ sapling } & \multicolumn{2}{|c|}{ small tree } & \multicolumn{2}{|c|}{ sapling } & \multicolumn{2}{|c|}{ small tree } \\
\hline & $\mathrm{F}$ & $p$ & $\mathrm{~F}$ & $p$ & $\mathrm{~F}$ & $p$ & $\mathrm{~F}$ & $p$ & $\mathrm{~F}$ & $p$ & $\mathrm{~F}$ & $p$ \\
\hline $\begin{array}{l}3000- \\
3100 \mathrm{~m}\end{array}$ & 18.08 & 0.003 & 109.35 & $<0.001$ & 1123.70 & $<0.001$ & 289.64 & $<0.001$ & 32.39 & $<0.001$ & 14.49 & 0.005 \\
\hline $\begin{array}{l}3100- \\
3200 \mathrm{~m}\end{array}$ & 34.40 & $<0.001$ & 129.53 & $<0.001$ & 468.09 & $<0.001$ & 68.05 & $<0.001$ & 28.11 & $<0.001$ & 21.94 & 0.002 \\
\hline $\begin{array}{l}3200- \\
3300 \mathrm{~m}\end{array}$ & 20.21 & 0.002 & 123.15 & $<0.001$ & 416.58 & $<0.001$ & 30.65 & $<0.001$ & 25.53 & 0.001 & 3.45 & 0.101 \\
\hline $\begin{array}{l}3300- \\
3400 \mathrm{~m}\end{array}$ & 7.51 & 0.003 & 89.24 & $<0.001$ & 65.67 & $<0.001$ & 20.08 & 0.002 & 1.13 & 0.383 & 1.30 & 0.340 \\
\hline $\begin{array}{l}3400- \\
3500 \mathrm{~m}\end{array}$ & 14.95 & 0.005 & 68.85 & $<0.001$ & 8.60 & 0.017 & 0.94 & 0.442 & 1.20 & 0.364 & 0.95 & 0.438 \\
\hline
\end{tabular}

Table 4 MANOVA analysis of the effects of elevation on three species regeneration density in the same size gaps. Significant effects $(p<0.01)$ are bolded. 


\begin{tabular}{lllllllll} 
Speices & & Large gap & \multicolumn{5}{c}{ Medium gap } & \multicolumn{2}{l}{ Small gap } \\
\cline { 2 - 8 } & & $\mathrm{F}$ & $p$ & $\mathrm{~F}$ & $p$ & $\mathrm{~F}$ & $p$ \\
\hline \multirow{2}{*}{ Abies faxoniana } & sapling & $\mathbf{2 2 . 4 3}$ & $<0.001$ & $\mathbf{1 7 . 2 2}$ & $<0.001$ & $\mathbf{4 0 . 0 6}$ & $<0.001$ \\
\hline & small tree & $\mathbf{2 5 . 0 6}$ & $<0.001$ & $\mathbf{2 5 . 3 6}$ & $<0.001$ & 2.63 & 0.098 \\
\hline \multirow{2}{*}{ Betula utilis } & sapling & $\mathbf{3 3 9 . 9 7}$ & $<0.001$ & $\mathbf{9 9 . 0 5}$ & $<0.001$ & $\mathbf{2 9 . 2 5}$ & $<0.001$ \\
\hline & small tree & $\mathbf{5 9 . 2 8}$ & $<0.001$ & $\mathbf{3 4 . 4 2}$ & $<0.001$ & 1.83 & 0.200 \\
\hline \multirow{2}{*}{ Acer maximowiczii } & sapling & $\mathbf{5 6 . 3 0}$ & $<0.001$ & $\mathbf{8 . 9 1}$ & $\mathbf{0 . 0 0 2}$ & $\mathbf{4 . 4 8}$ & $\mathbf{0 . 0 2 5}$ \\
\hline & small tree & $\mathbf{1 4 . 3 1}$ & $<0.001$ & 5.10 & 0.017 & 3.59 & 0.046
\end{tabular}

Table 5 The relationship between environment factors and species regeneration density at sapling and small tree life stage. Significant relationships $(p<0.05)$ are bolded. 


\begin{tabular}{|c|c|c|c|c|c|}
\hline sapling & small tree & sapling & small tree & sapling & small tree \\
\hline p & $p$ & $r$ & $p$ & $p$ & $p$ \\
\hline
\end{tabular}

PPFD

\begin{tabular}{lllllllllllll} 
Overcast & -0.16 & 0.349 & $\mathbf{0 . 7 2}$ & $<\mathbf{< . 0 0 1}$ & $\mathbf{0 . 5 9}$ & $<\mathbf{< . 0 0 1}$ & $\mathbf{0 . 5 5}$ & $<\mathbf{< . 0 0 1}$ & $\mathbf{0 . 4 5}$ & $\mathbf{0 . 0 0 4}$ & $\mathbf{0 . 4 6}$ & $\mathbf{0 . 0 0 3}$ \\
\hline Cloudless & 0.09 & 0.609 & 0.26 & 0.129 & 0.26 & 0.131 & 0.22 & 0.206 & 0.24 & 0.154 & 0.21 & 0.225
\end{tabular}

Air Temperature

\begin{tabular}{ccccccccccccc}
$\begin{array}{c}\text { Annual mean } \\
\text { temperature }\end{array}$ & $\mathbf{0 . 8 0}$ & $<0.001$ & 0.25 & 0.149 & $\mathbf{0 . 5 0}$ & $\mathbf{0 . 0 0 1}$ & $\mathbf{0 . 5 0}$ & $\mathbf{0 . 0 0 1}$ & $\mathbf{0 . 6 0}$ & $<0.001$ & $\mathbf{0 . 5 4}$ & $<0.001$ \\
\hline$\Delta \mathrm{T}_{\text {AMT }}$ & $\mathbf{0 . 5 8}$ & $<0.001$ & -0.42 & $\mathbf{0 . 0 0 8}$ & -0.20 & 0.246 & -0.23 & 0.185 & -0.09 & 0.600 & -0.12 & 0.508 \\
GST & $\mathbf{0 . 6 5}$ & $<0.001$ & 0.30 & 0.071 & $\mathbf{0 . 5 3}$ & $<0.001$ & $\mathbf{0 . 4 6}$ & $\mathbf{0 . 0 0 3}$ & $\mathbf{0 . 5 8}$ & $<0.001$ & $\mathbf{0 . 5 2}$ & $\mathbf{0 . 0 0 1}$ \\
NGST & $\mathbf{0 . 4 1}$ & $\mathbf{0 . 0 1 0}$ & -0.26 & 0.125 & -0.19 & 0.271 & -0.32 & 0.052 & -0.13 & 0.45 & -0.16 & 0.349
\end{tabular}

Air Humidity

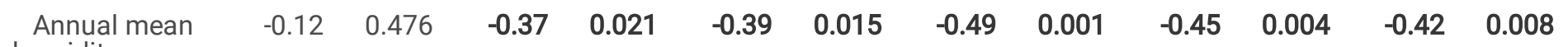
humidity

\section{Soil properity}

\begin{tabular}{|c|c|c|c|c|c|c|c|c|c|c|c|c|}
\hline $\begin{array}{l}\text { Soil } \\
\text { temperature } 0 \text { - } \\
10 \mathrm{~cm}\end{array}$ & 0.67 & $<0.001$ & 0.33 & 0.045 & 0.59 & $<0.001$ & 0.54 & $<0.001$ & 0.64 & $<0.001$ & 0.60 & $<0.001$ \\
\hline $10-20 \mathrm{~cm}$ & 0.62 & $<0.001$ & 0.41 & 0.010 & 0.65 & $<0.001$ & 0.60 & $<0.001$ & 0.69 & $<0.001$ & 0.66 & $<0.001$ \\
\hline $\begin{array}{l}\text { Soil total C (\%) } \\
0-10 \mathrm{~cm}\end{array}$ & 0.19 & 0.285 & 0.54 & $<0.001$ & 0.71 & $<0.001$ & 0.71 & $<0.001$ & 0.69 & $<0.001$ & 0.68 & $<0.001$ \\
\hline $\mathrm{cm} \quad 10-20$ & 0.27 & 0.103 & 0.51 & $<0.001$ & 0.60 & $<0.001$ & 0.43 & 0.007 & 0.54 & $<0.001$ & 0.52 & $<0.001$ \\
\hline $\begin{array}{l}\text { Soil total N (\%) } \\
0-10 \mathrm{~cm}\end{array}$ & 0.38 & 0.017 & 0.61 & $<0.001$ & 0.76 & $<0.001$ & 0.68 & $<0.001$ & 0.72 & $<0.001$ & 0.63 & $<0.001$ \\
\hline $10-20$ & 0.32 & 0.050 & 0.58 & $<0.001$ & 0.61 & $<0.001$ & 0.48 & 0.002 & 0.55 & $<0.001$ & 0.54 & $<0.001$ \\
\hline $\begin{array}{l}\text { Soil C/N } \\
\text { ratio(\%) } 0-10 \mathrm{~cm}\end{array}$ & -0.11 & 0.549 & 0.22 & 0.198 & 0.32 & 0.050 & 0.39 & 0.016 & 0.33 & 0.048 & 0.37 & 0.023 \\
\hline $10-20$ & 0.09 & 0.588 & 0.24 & 0.160 & 0.37 & 0.022 & 0.21 & 0.231 & 0.33 & 0.042 & 0.30 & 0.071 \\
\hline
\end{tabular}

Figures 


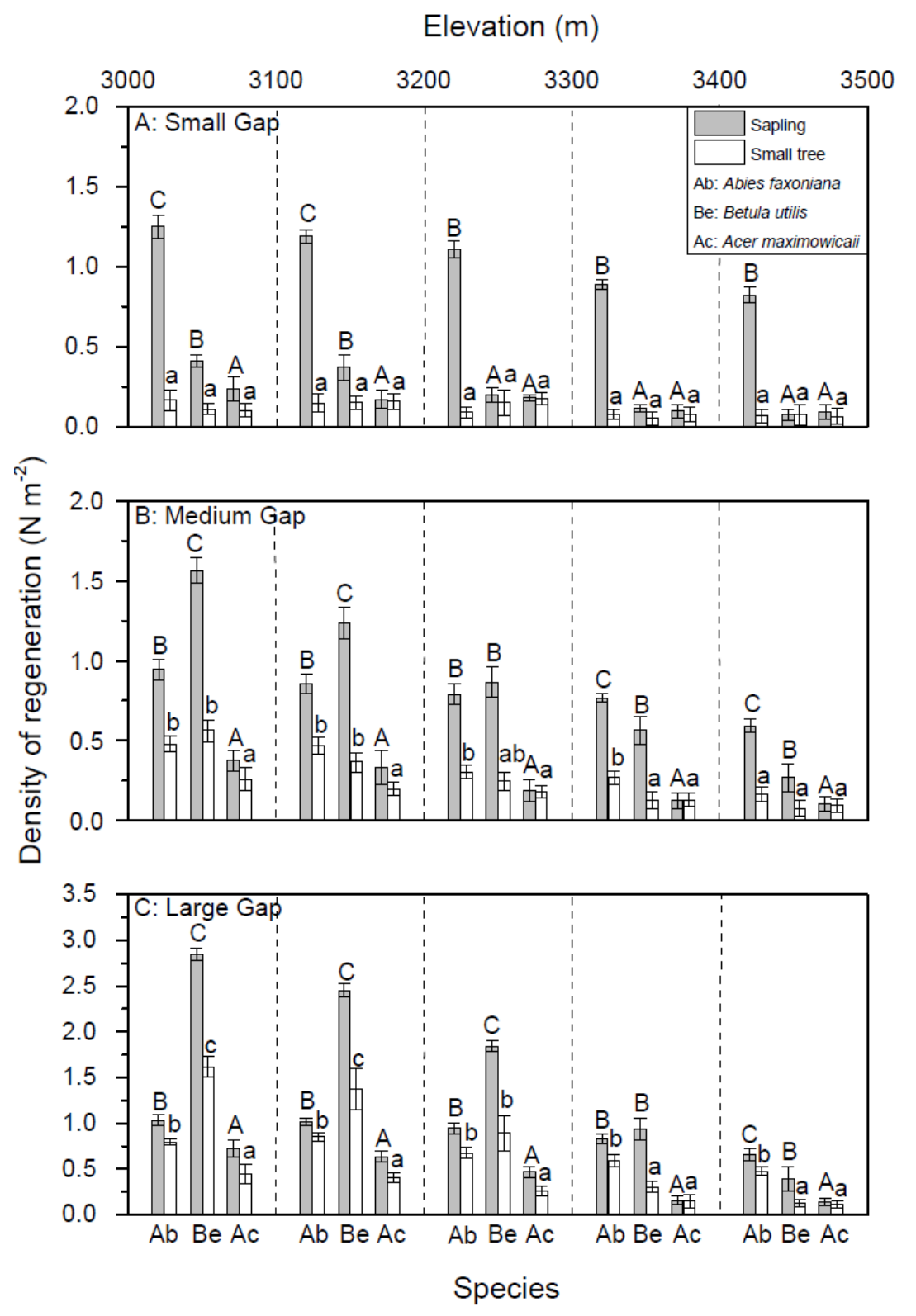

Figure 1

The results of one-way ANOVA analysis for three species sapling and small tree regeneration density in different size gaps at each elevation intervals. Different letters indicate significant difference $(p<0.05)$ among treatments. 


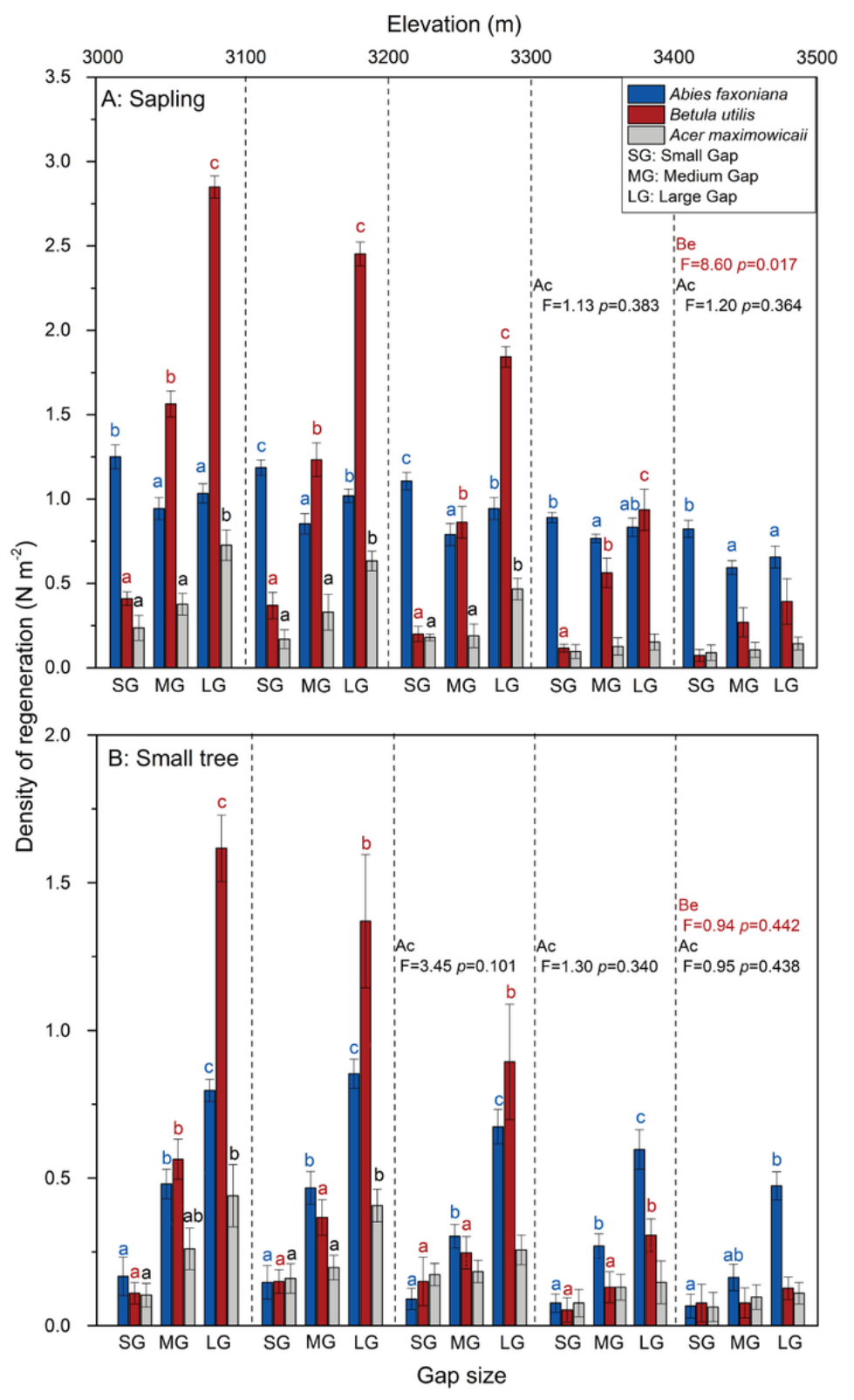

Figure 2

The MANOVA analysis for sapling and small tree regeneration density in different size gaps at each elevation intervals. Different letters indicate significant difference $(p<0.01)$ among treatments. 




Figure 3

The MANOVA analysis for sapling and small tree regeneration density in same size gaps along the elevation gradients. Different letters indicate significant difference $(p<0.01)$ among treatments. 